\title{
A ESPACIALIDADE DO DESENVOLVIMENTO BRASILEIRO EM QUESTÃO
}

Elson Luciano Silva PIRES ${ }^{1}$

\begin{abstract}
RESUMO
$\mathrm{O}$ artigo analisa a espacialidade do desenvolvimento brasileiro desigual, fazendo uma leitura crítica das vertentes teóricas do desenvolvimentismo economicista, procurando destacar a importância das teorias espaciais nas ciências sociais e justificar, por meio delas, o debate do desenvolvimento territorial e as prescrições da Política Nacional de Desenvolvimento Regional. Ao longo do artigo, procura-se fazer um contraponto com o debate das versões dos fatos nos governos FHC-Lula-Dilma, por meio de discussão resenhada dos trabalhos recentes sobre o modelo de desenvolvimento brasileiro predominante, neste limiar do século XXI.
\end{abstract}

Palavras-chave: Estado. Território. Desenvolvimento. Governança. Região.

\section{THE SPATIALITY OF BRAZILIAN DEVELOPMENT IN QUESTION}

\begin{abstract}
The article analyzes the spatiality of unequal Brazilian development, making a critical reading of the theoretical aspects of economic developmentism, seeking to highlight the importance of spatial theories in the social sciences and justify, for territorial development debate and the requirements of the National Regional Development Policy. Throughout the article, we seek to make a counterpoint with the debate of the versions of the facts in the FHC-Lula-Dilma governments, through a discussion reviewed of recent work on the predominant Brazilian development model, at this threshold of the 21st century.
\end{abstract}

Keywords: State. Territory. Development. Governance. Region.

\section{LA ESPACIALIDAD DEL DESARROLLO BRASILIERO EN CUESTIÓN}

\section{RESUMEN}

El artículo analiza la espacialidad del desarrollo desigual del Brasil, haciendo una lectura crítica de los aspectos teóricos del desarrollo económico, buscando resaltar la importancia de las teorías espaciales en las ciencias sociales y justificar, debate sobre el desarrollo territorial y los requisitos de la Política Nacional de Desarrollo Regional. A lo largo del artículo, buscamos hacer un contrapunto con el debate de las versiones de los hechos en los gobiernos del FHC-Lula-Dilma, a través de un debate revisado de los trabajos recientes sobre el modelo de desarrollo brasileño predominante, en este umbral del siglo XXI.

Palabras clave: Estado. Territorio. Desarrollo. Gobernanza. Región.

\footnotetext{
${ }^{1}$ Professor Titular do Departamento de Planejamento Territorial e Geoprocessamento e do Programa de Pós-Graduação em Geografia - IGCE - UNESP - Rio Claro.
} 


\section{INTRODUÇÃO}

O objetivo deste artigo é contribuir para o debate da agenda do desenvolvimento brasileiro. O desenvolvimento é um processo de transformação estrutural da sociedade que não pode ser confundido pelas políticas macroeconômicas, que visam ajustar a dinâmica econômica às flutuações de curto prazo. As políticas econômicas podem ajudar ou retardar processos que levem a transformações estruturais da economia, se caracterizando, portanto, como condições necessárias, mas não suficientes para promover o desenvolvimento.

O desenvolvimento de um país tem seu dinamismo condicionado pelas suas forças estruturais endógenas, que influem na forma em que cada sociedade, em dados momentos históricos, se organiza em torno de três questões essenciais: a federativa, a democrática e a socioeconômica. As formas e a ordenação da importância de cada uma destas questões são determinadas pela correlação de forças entre as diversas frações das classes sociais, especialmente nas políticas hegemônicas que se destacam no poder do Estado em cada momento da história. O Brasil, no longo prazo, teve vários regimes políticos e de acumulação, em que algumas vezes a questão nacional, associada ou não à questão federativa, ou a questão democrática e social, tornaram-se os principais temas nos debates e disputas políticas. Um desses momentos mais frutífero foi o período Lula-Dilma, fruto do governo de coalizão de centroesquerda sob a liderança do Partido dos Trabalhadores (PT).

As teorias desenvolvimentistas que procuram mostrar os fatores explicativos desses processos históricos do desenvolvimento brasileiro, embora todas elas destaquem a importância da ideologia dos governos e dos partidos políticos no poder, deixam de lado a realidade da fragmentação espacial do território nacional entre diferentes regiões, dividido entre estados e municípios portadores de autonomia política e constitucional (União, estados e municípios). A afirmação explícita da necessidade de inclusão da questão federativa na formulação da política econômica nos remete a política de organização jurídica do Estado, objetivo de conflitos de interesses poderosos que aqui se expressam na questão "regional" da questão "nacional". 
Diante deste pressuposto crítico mais geral, propõe-se fazer um contraponto teórico e metodológico alternativo às formulações economicistas e aos fatores explicativos das "teorias desenvolvimentistas", reconhecendo que a noção de desenvolvimento requer uma compreensão mais complexa de sistemas que combinam as instituições econômicas com as sociais, culturais e políticas, nas quais as interações mudam ao curso dos tempos e ao longo da superfície terrestre. Em consequência, as intervenções do Estado e dos agentes com seus ambientes devem ser multiformes, no tempo e no espaço. O que é bom para uma fase do desenvolvimento pode ser desfavorável posteriormente. Da mesma forma, o que é bom para um determinado país pode ser desfavorável para outro. Certas irreversibilidades criam dependências em relação ao caminho, no tempo e no espaço. Portanto, as prescrições endereçadas a um país dado em uma época precisa devem estar ancoradas na compreensão da sua realidade específica, da trajetória que o conduziu ao presente, através do tempo historicamente longo.

Nesta perspectiva, a análise da espacialidade do desenvolvimento brasileiro deve considerar os ativos e recursos patrimoniais naturais e artificiais, distribuídos e inscritos nas diferentes regiões e territórios, no seu meio rural e em processo de urbanização, urbano e metropolitano. Ela obriga o(a) pesquisador(a) a fazer uma abordagem combinada da geografia com a economia, articulada às ciências sociais, cujo objetivo é identificar uma cesta das necessidades humanas nas diferentes escalas regionais e territoriais, suas causalidades e finalidades, seus conflitos e os papéis das instituições econômicas, culturais e políticas que influenciem no desenvolvimento do território.

Esta leitura transversal do desenvolvimento brasileiro permite ultrapassar os limites e dilemas dos mecanismos clássicos de regulação dicotômica do desenvolvimento, como o Estado e o mercado, para introduzir o papel da sociedade civil, através de arranjos institucionais intermediários como as comunidades e associações locais, necessários para a construção de territórios socialmente organizados. Nesses casos, o Estado (poder público), o mercado (setor privado) e a sociedade civil comunitária seriam os três agentes capazes de coordenar e propor soluções para resolver os grandes conflitos, 
promoverem planos e assumirem o papel de agente do desenvolvimento, e das mudanças estruturais.

As dinâmicas territoriais implícitas a esses processos resultam da coordenação possível de duas estratégias. Por um lado, da construção de um projeto coletivo de desenvolvimento territorial definido e colocado em ação pelos atores públicos e privados; esse é um novo campo para as políticas públicas locais. Por outro lado, da perspectiva das empresas, desenvolver estratégias de utilização dos recursos locais a fim de otimizar suas condições de produção ou de criação de novos recursos. Assim, podem-se distinguir dinâmicas dos territórios dirigidas por todos os atores em torno de poderes públicos e de estratégias de empresas, que podem ou não utilizar os recursos locais comunitariamente. Esses dois processos não se opõem e podem mesmo se combinar expressando os interesses comuns do território através de instituições formais e informais. Eles são alternativos às estratégias unilaterais dos governos municipais de atração de empresas com base na guerra fiscal. Ao contrário, as empresas deveriam ser atraídas pelas potencialidades e especificidades do território, isto é, por uma competitividade territorial ativa, e não pelas concessões e isenções fiscais, doações de terrenos etc., típico da competitividade territorial passiva. Nesse sentido é que o debate da governança do desenvolvimento territorial se pauta em um equilíbrio necessário e complementar entre o Estado, o mercado/empresas e a sociedade civil/comunidade.

Estas reflexões sugerem uma leitura transversal do desenvolvimento brasileiro, que são apresentadas neste artigo em três seções, visando destacar a relevância da dimensão espacial/territorial no debate das nossas estratégias de desenvolvimento nos governos Lula-Dilma. A primeira seção, de caráter mais geral e com função de suporte às seções seguintes, aborda de forma sucinta os fatores explicativos do desenvolvimento, o alcance das teorias desenvolvimentistas e suas implicações na trajetória do desenvolvimento brasileiro recente. A segunda seção preocupa-se com os aspectos sociais e econômicos mais ou menos implícitos nas lógicas espaciais do desenvolvimento territorial, ao estabelecer as relações entre as escalas, os atores, os recursos inovações, competitividade, solidariedade e cidadania - e as possibilidades de 
pô-los em marcha. A terceira seção recupera o processo inacabado da tentativa de construção da Política Nacional de Desenvolvimento (PNDR), para reconciliá-la com as origens e os fatores explicativos da regulação do desenvolvimento territorial recente, com base no papel do Estado e no aproveitamento das potencialidades e especificidades das sociedades locais e regionais. A quarta seção conclui o artigo.

\section{OS FATORES, AS TEORIAS E AS POLÍTICAS DE DESENVOLVIMENTO NO BRASIL}

\section{Os fatores explicativos do desenvolvimento}

No final do século XX, os estudos da OCDE (1995) citavam quatro fatores básicos que, no longo prazo, explicam em larga medida como os aumentos na produção per capita poderiam ser registrados nos diferentes países. São eles: (i) o progresso técnico, a inovação e o espírito empreendedor; (ii) a acumulação do capital físico: os meios de produção, nos quais o progresso técnico deve normalmente se inserir; (iii) o capital humano: melhoramento das competências humanas, do nível de educação e das capacidades organizacionais; (iv) a abertura e a integração mais estreita das economias nacionais para trocas de bens e serviços, por investimentos e ligações entre interesses intelectuais e interesses industriais.

Estes fatores socioeconômicos necessários mostraram-se básicos, mas tornaram-se insuficientes para explicar o desenvolvimento humano e social na variedade de capitalismos vigentes no início do século XXI. O que as análises institucionalistas das trajetórias nacionais de desenvolvimento mostram, é que são valores sociais e formas institucionais socioeconômicas e políticas, que desempenham papéis preponderantes nos processos de desenvolvimento, como outros fatores que, no longo prazo, parecem consolidar as novas estratégias do desenvolvimento. São eles: (v) a formação do capital: a taxa de investimento, bom sistema de alocação pelos preços e harmonia das instituições de base da economia capitalista - regime monetário, formas da concorrência e relação salarial; (vi) a qualidade da governança do Estado do território nacional; (vii) a ausência de corrupção; (viii) a democracia e a participação social; (ix) a 
promoção dos direitos e da liberdade do cidadão; (x) a sustentabilidade ambiental e ecológica diante da raridade ou escassez relativa dos recursos naturais (SEN, 1999; BOYER, 2001; GUELLEC, RALLE, 2001).

De maneira positiva, para qualquer país capitalista, o debate dos novos fatores explicativos do desenvolvimento afasta a possibilidade de um fator único determinante, pois obriga o pesquisador analisar as instituições e as estruturas de valores de uma sociedade ou um país, e suas inter-relações em uma abordagem interdisciplinar e sistêmica. Segundo Adelman (2001:104-105 apud BOYER, 2001:14),

uma política de desenvolvimento requer uma compreensão mais complexa de sistemas que combinam as instituições econômicas, sociais, culturais e políticas, nas quais as interações mudam ao curso dos tempos. Em consequência as intervenções devem ser multiformes. O que é bom para uma fase do desenvolvimento pode ser desfavorável posteriormente. Certas irreversibilidades criam dependências em relação ao caminho. As prescrições endereçadas a um país dado, em uma época precisa, devem estar ancoradas na compreensão da sua situação, da trajetória que o conduziu ao presente, através do tempo historicamente longo.

Estas análises têm contribuído para demonstrar a existência de vários tipos de capitalismos no mundo, fundamentais para pensar as possibilidades reais dessas economias e reformular suas estratégicas de desenvolvimento.

No Brasil, como veremos a seguir, os estudos pesquisados mostram resultados medianos entre o primeiro grupo de fatores e resultados insatisfatórios no segundo grupo. $\mathrm{O}$ avanço das condições socioeconômicas tem sido superior às condições institucionais do desenvolvimento, ancorado em um passado histórico recheado com déficits permanentes: econômicos, sociais e políticos.

\section{As teorias desenvolvimentistas no Brasil contemporâneo}

Sob o manto do conceito de novo-desenvolvimentismo, além da teorização clássica antecessora da CEPAL, tem surgido no Brasil três grandes vertentes precursoras, com visões teóricas e programas econômicos e políticos conflitantes. Ao todo, são quatro interpretações que mobilizam as mentes e corações dos seus defensores mais apaixonados. 
1) o antigo desenvolvimentismo antecessor, inaugurado por Raul Prebisch (1961, p. 7-10) e Celso Furtado (1961, p. 31, 47) e associado aos trabalhos iniciais da CEPAL, mas também próximo do pensamento neoclássico, prioriza o mercado interno na superação do subdesenvolvimento, destacando o papel das poupanças e da intervenção do Estado, em articulação com os investimentos privados;

2) o novo-desenvolvimentismo precursor, associado aos trabalhos de Bresser-Pereira (2016, p. 669-670) e também com forte influência do pensamento neoclássico ortodoxo, distante de traços estruturalistas, enfatiza a industrialização "orientada para as exportações" como o elemento dinâmico na superação do subdesenvolvimento, mas destaca o equilíbrio interno dos principais preços macroeconômicos (ou formas institucionais) - taxa de lucro, taxa de câmbio, taxa de salários, taxas de juros e taxa de inflação - com ênfase na taxa de câmbio;

3) o novo-desenvolvimentismo pós-keynesiano, com forte influências do pensamento de Keynes, próximo ao chamado "neodesenvolvimentismo", está associado aos trabalhos de Sicsú $(2007,2017)$ e chamam a atenção para a adoção de um conjunto de medidas que visam aumentar o nível de demanda agregada para criar um ambiente estável que estimule os empresários a realizar novos investimentos, através da atuação do Estado para evitar a vulnerabilidade externa decorrente da liberação dos fluxos financeiros entre os países, e a gestão da política fiscal e monetária na articulação dos blocos de capitais e do investimento autônomo ou descontínuo de grandes empresas. Por isso a variável-chave é a taxa de juros (e não a taxa de câmbio), que precisa ficar baixa para ao mesmo tempo estimular o investimento e desestimular a entrada de capitais especulativos, que apreciam a moeda nacional com todas as suas consequências nefastas; e

4) o social-desenvolvimentismo, associado aos trabalhos de Bielschowsky (2012), Bastos (2012), Mollo e Amado (2015) e Gabrielli de Azevedo (2017), destaca a importância fundamental das políticas de distribuição e transferência de rendas para os mais pobres, como indutoras da dinâmica do mercado interno de massas e da questão social, com maior ênfase nas questões distributivistas e na inserção dos trabalhadores no mercado de trabalho em diferentes qualidades 
e qualificações. Resgatando a tradição marxista do processo de acumulação capitalista, a ideia é que como o desenvolvimento duradouro depende da poupança financiando o investimento, e como esta sai dos lucros, não é possível conceber como viável um crescimento estimulado apenas por aumentos de salários, independente da produtividade do trabalho. Diferente das demais concepções, a variável-chave para o social-desenvolvimentismo é a produção e o consumo de massas, com ganhos de produtividade que permitam aumentar os rendimentos de escala, o progresso técnico e ainda a elevação dos salários.

No plano da estratégia política, de uma maneira geral, estas quatro visões das teorias desenvolvimentistas consideram uma autonomia para o Estado e a intervenção pública no capitalismo, se contrapondo em relação a uma visão leninista mais ortodoxa do Estado serviçal dos interesses das classes dominantes e frações hegemônicas da classe capitalista (POULANTZAS, 1980; MOLLO, 2001; JESSOP, 2009). Em especial, para os desenvolvimentistas postkeynesianos e os sociais-desenvolvimentistas, inspirados em Poulantzas (1980, p. 152-153), o Estado é uma instituição jurídica e política em disputa, uma "condensação de uma relação de forças", no qual é possível a formulação e implantação de políticas que impactem a distribuição de renda, especialmente a redução da pobreza. Sugerem três dimensões para a luta contra hegemônica visando à transformação da sociedade: ampliação dos canais de escuta das classes populares, a busca de maior igualdade de renda, consumo e capacidade de decisão dentro da sociedade atual e a organização e execução de processos de autogestão da produção.

Um dos elementos fundamentais desta nova agenda socialdesenvolvimentista é a abertura de canais que possibilitem aos segmentos populares da sociedade, fora do bloco do poder, influir na formulação e execução de políticas públicas, uma vez que o Estado é considerado um espaço em disputa com os grupos dominantes. Os mecanismos de democracia participativa são parte inerente do processo de acumulação de forças para as transformações contra hegemônicas partindo da sociedade para o Estado. Nessa perspectiva, os avanços da democracia participativa dependem fortemente da correlação de forças entre as classes sociais e o Estado na disputa política em 
cada conjuntura, muito presente neste momento histórico e institucional recente refletido nos governos Lula e Dilma.

Nas teorias desenvolvimentistas, enquanto o ambiente macroeconômico permeia a maioria dessas análises e o debate macrossocial permeia a afirmação identitária, surpreende como a questão regional é desconsiderada como uma questão menor, na margem, quase sempre ausente.

Para o debate da importância da questão espacial na formulação de uma abordagem interdisciplinar do desenvolvimento brasileiro desigual, embora nenhuma dessas teorias desenvolvimentistas seja explícita com relação a esta questão no Brasil, os efeitos da perspectiva social-desenvolvimentista repercutem melhor nas expectativas da análise da diversidade e das especificidades das regiões brasileiras, através dos efeitos regionais desiguais implícitos nas políticas macroeconômicas, além das dimensões territoriais implícitas nas formulações das políticas setoriais e de isenção fiscal. $\mathrm{O}$ aumento do investimento precisa ser priorizado entre as medidas de política econômica, mas também a escolha do seu local ou região beneficiada, para garantir o crescimento equilibrado da produção e do emprego entre as cidades e regiões do país.

Portanto, é na crítica a este ambiente implicitamente homogêneo e isomorfo das teorias desenvolvimentistas do desenvolvimento brasileiro nacional, aos fatores explicativos e as formas organizacionais e institucionais, seus meios e fins nas transformações da sociedade, que ressurge a importância das escalas no Estado federativo e faz emergir as novas possibilidades do desenvolvimento regional e territorial. Este pode ser entendido como um processo de mudança social de caráter endógeno, capaz de produzir solidariedade e cidadania comunitária, e de conduzir de forma integrada e permanente a mudança qualitativa e a melhoria do bem-estar da população de uma localidade ou de uma região. O processo de desenvolvimento territorial é dinamizado por expectativas de agentes locais/regionais, nas quais o território seria o agente/ator principal do desenvolvimento, e as políticas públicas, as instituições, as organizações e as governanças seriam os recursos específicos, a um só tempo disponível e a serem criados (inventados e/ou inovados) no local ou região, ou nos mais diversos elos da rede mundial. O desenvolvimento 
territorial é o resultado de uma ação coletiva intencional de caráter local e específica, portanto, uma ação associada a uma cultura, a um plano e instituições locais, tendo em vista arranjos de regulação das práticas sociais. (PIRES; MULLER; VERDI, 2006, p. 448).

\section{A trajetória do desenvolvimento econômico e político brasileiro na era dos presidentes Lula e Dilma}

Na onda do crescimento das organizações civis e da oposição ao segundo mandato de Fernando Henrique Cardoso, a eleição e reeleição do Presidente Lula, e, posteriormente, da presidente(a) Dilma, pareciam dar início à construção de um novo modelo político e econômico para o Brasil, diferente dos vigentes no auge da época neoliberal. Nesse período, no governo federal, a questão social e o desenvolvimento econômico dominaram a conjuntura.

No período de 2004-2014, os governos Lula e Dilma pilotaram a política econômica, tentando conciliar duas ordens contraditórias de interesses: de um lado, a (des)ordem da acumulação rentista-financeira e do setor exportador de commodities, e, de outro, a acumulação produtiva industrial e agrícola, com políticas sociais redistributivas e de inclusão social via consumo (por exemplo, o programa Bolsa Família, aumentos reais do salário mínimo, expansão do consumo popular via crédito etc.) (BRUNO, CAFFÉ, 2017, p. 1037). Em consequência, a lógica da financeirização e do consumo aproveitou-se das políticas sociais do Estado, promovendo ao longo dos anos o endividamento das famílias e o aumento da insegurança e vulnerabilidade social (LAVINAS, 2017).

Apesar das oscilações da política econômica desses governos, a economia brasileira aprofundou a sua segunda fase de um modelo neoliberal-dependente iniciado no governo FHC, com a contínua inserção internacional subordinada aos mercados globais. O Estado brasileiro e suas estruturas encontram-se hoje gravemente afetados pelo poder das finanças e, consequentemente, pelas expectativas e interesses dos grandes grupos econômicos que se beneficiam diretamente da acumulação rentista-patrimonial (BRUNO, CAFFÉ, 2017, p. 1026).

Alguns autores economistas destacam as razões do baixo ritmo de crescimento do país na transição entre o século passado e o início deste século 
XXI como resultado da continuidade do regime liberal, com populismo cambial e dependência da poupança externa, apesar dos governos distintos de Fernando Henrique, Lula e Dilma (BRESSER-PEREIRA, 2016; BRUNO, CAFÉ, 2017). Diferentemente, outros autores fazem uma avaliação das diferenças da experiência dos Governos Lula e Dilma, trazendo um conjunto de ensaios sobre vários aspectos da intervenção do Estado nesses governos, destacando seus impactos na ampliação da democracia, das políticas sociais e identitárias (MARINGONI, MEDEIROS, 2017). Na maioria desses estudos, as análises mostram que a desigualdade mudou pouco, chegando a aumentar em alguns casos. A maioria desses autores são bastantes críticos ao caráter limitado das mudanças implementadas por esses governos.

No primeiro mandato do Presidente Lula, os primeiros estudos críticos já mostravam um curioso fenômeno de despolitização das questões da pobreza e da desigualdade, inclusive da "questão regional". O Governo Lula vai transformar estas questões em problemas administrativos, cooptando os movimentos sociais e as organizações da sociedade civil para dentro do Estado. Parecia que parte "dos de baixo" dirigia o Estado por intermédio do programa "dos de cima", inaugurando uma espécie de dominação que Oliveira (2010, p. 25) chamou de "hegemonia às avessas". Esta nova fase da política brasileira que se estende até 2014, não teria nada parecido com o antigo patrimonialismo, o patriarcalismo e o populismo. Parece que nada disso esteve presente na nova dominação em curso na época. O chamado "lulismo", um fenômeno novo e contraditório, teria se estabelecido na política neoliberal brasileira, de 2003 até 2014 (SINGER; LOUREIRO, 2016). A partir desses estudos, é possível supor uma espécie de neoliberalismo às avessas no Brasil, submisso à financeirização da economia globalizada com forte intervenção do Estado nas políticas econômicas e sociais.

Diante deste componente da economia política brasileira, para Paulani (2017, p. 91, 99), os governos Lula e Dilma revelaram um caráter errático e foram oscilantes na política econômica e social, pois não tiveram um projeto nacional de desenvolvimento estratégico. $\mathrm{Na}$ ausência de um projeto que se configurasse como tal, o planejamento também não existiu, porque não se fez necessário. Os governos caminharam ao sabor das conjunturas, se preocupando 
em administrar o capitalismo brasileiro neoliberal, sem ameaçar o status quo da acumulação financeira, a qual, nos cinco mil dias de governo, não foi enfrentada, de modo decisivo, em nenhum momento. A autora agrupa a rota oscilante em quatro períodos: inicialmente, de 2003 a 2006, na fidelidade integral aos cânones da prescrição ortodoxa (Carta aos brasileiros e anos Palocci); na sequência, de 2006 a 2010, na inspiração desenvolvimentista (anos PAC); terceiro, de 2011 a 2013, na reação embaralhada de ortodoxia com pitadas de heterodoxia, mas talvez menos desenvolvimentista que a etapa anterior, no primeiro período de Dilma; e quarto, de 2014-2015, novamente um retorno forte à ortodoxia nos últimos dezesseis meses de governo petista (com Joaquim Levy assumindo o Ministério da Fazenda). Para Paulani (2017, p. 99), esse vaivém, esse bate-cabeça é a aprova maior de que faltava aí um projeto de desenvolvimento nacional - de preferência nacional, popular e democrático, que tivesse permitido, desde seu início, o planejamento da intervenção econômica.

Esta ausência de um projeto de desenvolvimento sem intervenção coerente e planejada da política econômica, é resultado das dificuldades inerentes ao presidencialismo de coalizão vigente no país, agravado com a Constituição de 1988. Nos governos FHC-Lula-Dilma, o presidencialismo de coalizão produziu boas políticas públicas: o fim da hiperinflação, com o Plano Real, e a redução da pobreza e desigualdade, com as políticas de transferência de renda aos mais pobres, como o Bolsa Escola ao Bolsa Família. Mesmo assim, este modelo gerou enormes déficits que impedem nosso progresso em sintonia com as transformações globais em aceleração deste século.

Como a política republicana brasileira sempre foi plural, fragmentada e cheia de facções, a adoção de um tipo de modelo econômico e político não é uma questão de simples escolha ou pura vontade. Para o cientista político Sérgio Abranches (2018, p. 15), havia e continua a haver disparidades de comportamento na sociedade brasileira, que vão das formas mais atrasadas de clientelismo até padrões ideologicamente orientados. Como não temos uma cultura de negociação que promova sínteses inovadoras, a história brasileira tem mostrado que, em geral, a solução sai de alguma forma de compromisso que adia o enfrentamento de conflitos e de clivagens enraizadas em nosso tecido 
social, e que não promove as rupturas necessárias ao avanço efetivo rumo a padrões mais avançados de convivência política e social. Imaginar que, se substituirmos o tipo de desenvolvimento e de presidencialismo de coalização por outros modelos resolveriam todos os nossos problemas de fundo e estrutura, é uma ilusão que pode ter consequências contrárias. A possibilidade de conseguir avanços significativos de qualidade com reformas eleitorais é mais duvidosa ainda.

Segundo o economista Gabrielli de Azevedo (2017, p. 12), mesmo não promovendo várias reformas estruturais essenciais para as mudanças do desenvolvimento, caracterizar os governos Lula e Dilma como liberais, é outra questão. Para este autor, seguindo o raciocínio de Paulani (2017), os governos Lula e Dilma podem ser classificados por várias oscilações de política econômica, ora mais liberais, ora mais desenvolvimentistas, sem um programa global que objetivasse a quebra das relações de poder da sociedade, no sentido de quebra estrutural das relações de propriedade e predomínio do capital privado na acumulação. Muitas vezes as mudanças de políticas eram reativas a mudanças de conjuntura externa, bem mais do que estruturantes de um projeto nacional de distribuição de renda. Todas as vezes em que houve mudanças de orientação, a correlação de forças entre as classes sociais foi determinante para as escolhas. As poucas mudanças na questão democrática não permitiram avançar na pauta de redução de desigualdades, com crescimento. Portanto, longe de um modelo liberal de governo, os governos de Lula e Dilma optaram por viabilizar programas e políticas que buscassem enfrenta a Dimensão Social das conjunturas como principal, numa aliança com o capital financeiro e produtivo, que só teria viabilidade de curto prazo, mas que foi erroneamente tomada como permanente. Vários mecanismos de intervenção do Estado, possíveis em um momento de crescimento e sem as limitações de divisas internacionais, foram adotadas, deixando de lado as reformas estruturais que modificassem a correlação de forças na gestão do Estado e apropriação das rendas e riquezas do país. Diferente de um modelo liberal intervencionista, o papel do Estado era central nestas políticas.

Segundo Bastos (2017, p. 77), apesar da "carta ao povo brasileiro", Lula cometeu três heresias em relação ao neoliberalismo: i) vetou novas 
privatizações, ii) restaurou o papel ativo dos bancos públicos para execução de políticas de desenvolvimento produtivo e expansão do mercado interno; e iii) resgatou a política do salário mínimo, os direitos trabalhistas e a política social. Para Sicsú (2017, p. 14), o governo Lula também destoou da agenda liberal no papel dos bancos públicos, fortalecendo o BNDES, a Caixa e o Banco do Brasil. O BNDES deixou de apoiar os programas de privatização para financiar investimentos produtivos em setores específicos, alguns deles resultando em apropriação inadequada de recursos pelos "campeões nacionais". Além dos programas de Benefício de Prestação Continuada e do Bolsa Família, o crédito direto se expandiu para a agricultura familiar, os programas habitacionais e de saneamento, o agronegócio, as empreiteiras e ao consumidor. No que se refere ao petróleo e gás, os governos Lula e Dilma também fizeram mudanças profundas no papel do Estado, fortalecendo o sistema Petrobrás para a consolidação de uma cadeia de fornecedores instalada no Brasil.

No que se refere à dimensão estritamente democrática das conjunturas, como retomaremos adiante, foram adotados mecanismos de participação direta da população e da sociedade civil, na governança do Estado e na implantação de mecanismos de viabilização dos direitos conquistados na Constituição de 1988, mesmo que sua eficácia e eficiência possam ser questionadas. Nos governos Lula e Dilma, centenas de conselhos, conferências e mecanismos de escuta foram implementados.

Diante deste componente da economia política brasileira, faltaram aos governos Lula e Dilma uma visão de futuro, um projeto de longo prazo para o país. Daí a oscilação das políticas. Eles foram reféns da hiperfragmentação partidária, pois esta afeta diretamente a formação de coalizões ideológicas, o seu tamanho e a probabilidade de serem estáveis, além de propiciar terreno fértil para o clientelismo e a corrupção. A fragmentação reflete o aumento excessivo do número de partidos com poder de veto e impõe coalizões mais extensas e heterogêneas, mesmo que o presidente se contentasse com uma coalizão natural, de maioria simples. Este quadro abre brechas à corrupção como forma de satisfazer parceiros clientelistas em número elevado (ABRANCHES, 2018, p. 345). A excessiva concentração de poderes discricionários na Presidência da República - legislativos e fiscais - foi outro elemento essencial de estímulo ao 
clientelismo e à patronagem, ao toma-lá-dá-cá. Esses legados autoritários, convertidos à democracia representativa, metamorfoseiam o Congresso em poder pedinte e o Executivo em poder concedente. Cria-se um ambiente propício à barganha e à chantagem recíproca, que tende a eliminar ou elidir relações de confiança, afinidade programática ou convencimento ideológico (ABRANCHES, 2018, p. 372).

Para Abranches (2018, p. 371), nosso sistema político-econômico encontrou no presidencialismo de coalizão os instrumentos para reprodução do domínio oligárquico, por meios mais ou menos legítimos, mais ou menos lícitos. As oligarquias partidárias se perpetuam no poder e mantêm o fluxo de subsídios que alimenta a oligarquia empresarial. Seja nos governos do Partido da SocialDemocracia Brasileira (PSDB), seja nos governos do PT, a maior fatia da renda pública foi transferida para os mais ricos, os capitalistas, via BNDES, Banco do Brasil, Caixa Econômica, Receita Federal e outros dutos subsidiários. Por outro lado, o sistema econômico neoliberal avança na sociedade brasileira, pois se alimenta da intervenção seletiva do Estado para interesses dos mais ricos e para fomentar o individualismo crescente para promover a competição entre os mais pobres.

Diante deste quadro complexo, são raros os projetos de governo de curto prazo que provocam grandes mudanças. Do ponto de vista constitucional, não há princípio de política pública que possa ter validade perpétua, sobretudo no imprevisível longo prazo. O caminho possível é pensar em regras universais, igualitárias, abstratas e gerais, que defendam os fundamentos republicanos e democráticos indispensáveis à realização, a qualquer tempo, dos princípios fundadores da liberdade, da igualdade e da fraternidade (ABRANCHES, 2018, p. 86).

Nesse contexto de possibilidades das transformações sociais possíveis, o Brasil precisa ir além das políticas econômicas e das reformas políticas, para romper o cerco oligárquico por meio de amplo realinhamento das forças políticas e do sistema partidários. Como não existe lei ou regra eleitoral que promova essa transformação, Abranches (2018, p. 3743-4) argumenta que o Brasil precisa livrar-se da obsessão por reformas e emendas, para começar a resolver estruturalmente os problemas que nos impedem de avançar no século 
XXI, com mais qualidade e maior capacidade de enfrentar os imprevistos desafios da grande transição que atravessamos.

Nesse ambiente sociológico, a dinâmica do sistema político aliado ao modelo econômico neoliberal, não deve ser vista como a única fonte de pressões para o desenvolvimento econômico. A heterogeneidade e o desenvolvimento brasileiro desigual geram demandas do mercado (setor privado) além da capacidade corrente do Estado para satisfazê-las. Elas atuam na estrutura de preços e de incentivos, para manter seus privilégios. Essas demandas concorrem com as demandas da sociedade civil e da sociedade política, na distribuição do orçamento público do Estado. O grande problema estrutural é que o quadro institucional brasileiro não gera, como regra, políticas públicas de qualidade, não garante a alocação equânime de recursos e serviços públicos, nem oferece ao cidadão continuidade das políticas públicas, ou estabilidade de regras e procedimentos. Os resultados insatisfatórios dos indicadores sociais e ambientais comprometem gravemente a qualidade de nossa democracia e bloqueia o desenvolvimento sustentável do país.

Como foi visto até aqui, os problemas da correlação de forças, do presidencialismo de coalizão, que envolvem os estados da federação e as regiões geográficas do país, são apenas mencionados na vertente socialdesenvolvimentista. O território nacional brasileiro, fragmentado e desigual, não aparece de forma explícita em nenhum dos estudos desenvolvimentistas. Ele está implícito ou na margem das formulações. Nas análises das políticas econômicas, o território nacional é considerado homogêneo e isomorfo. Os atores hegemônicos estão presentes, mas não existem fissuras, escalas das ações nem regionalismos culturais.

Se por um lado é importante ressaltar que as novas relações sociais, capitaneadas pelos governos do Partido dos Trabalhadores, criavam as condições para que o processo de financeirização brasileiro estendesse seu espaço de valorização rentista-patrimonial, expandindo as operações de crédito em todas as classes e regiões do país, incluindo aqui o programa "Bolsa Família”, por outro lado, reforçavam-se os mecanismos de participação social e criavam-se outros, que permitiriam uma descentralização forçada do poder e das políticas públicas de desenvolvimento regional, em confronto aberto com o 
modelo centralizador dominante. Nesse sentido, a política econômica ao ativar o consumo da população deslanchou a expansão de mecanismos de cooperação e coordenação da espacialidade do desenvolvimento brasileiro desigual. Nesse processo de ampliação da participação social nos governos, dava-se início a construção de novas escalas e modalidades de governança territorial local e regional (câmaras, comitês, circuitos, conselhos, fóruns) e a criação da nova Política Nacional de Desenvolvimento Regional (PNDR), não capitaneadas pelas teorias desenvolvimentistas (PIRES et al., 2011).

Passados doze anos de governos do PT, apesar dos avanços sociais e econômicos, registrados em estudos e demonstrados nas estatísticas oficiais, desde a Carta do PT aos brasileiros em 2002, às vésperas das eleições em 2003, a oscilação errática da política econômica com continuidade do pragmatismo dos governantes impossibilitou a construção de uma contra hegemonia neoliberal e de transformações estruturais logradas, mas também daquelas que sequer não foram realizadas (SADER, 2013; SINGER; LOUREIRO, 2016; MARINGONI; MEDEIROS, 2017). Nesse período, a perspectiva do desenvolvimento econômico brasileiro continuava aliada ao grande desafio de nossa democracia, que continua sendo, apesar dos avanços, sua institucionalização com legitimidade. (ABRANCHES, 2018, p.11)

\section{AS ESCALAS DE PODER E AS GOVERNANÇAS TERRITORIAIS DO DESENVOLVIMENTO BRASILEIRO}

Conhecida como o fator espacial da acumulação e do desenvolvimento capitalista, a questão das escalas de base é tratada na economia espacial e na geografia econômica e regional há muito tempo; desde Von Thünen no século XIX até os dias atuais, embora de diferentes maneiras. O estudo da relação espaço, economia e sociedade necessita, enquanto uma dimensão da reprodução social, cada vez mais ser reconhecida, na medida em que os problemas atuais da sociedade se vinculam estreitamente às questões de natureza espacial (GOTTDIENER, 1993; SANTOS, 1996; HARVEY, 2001) e da espacialidade do desenvolvimento (SMITH, 1988), problemas estes que foram ampliados pela globalização (BENKO, 1996). 
Sem se aprofundar na questão, as escalas do desenvolvimento podem ser colocadas hoje em quatro níveis: o local ou regional, o nacional, o bloco transnacional e o mundo globalizado. A escala local é determinante para o desenvolvimento. As escalas sub-regional e regional adquirem novos papéis na globalização, de resistência regional da uniformização, da banalização espacial. A escala nacional, ligada à noção de Estado-Nação, permanece fundamental para o desenvolvimento. Trata-se de um conjunto estruturado de leis, de projetos comuns e de uma organização territorial mais ou menos coerente, de uma política de afirmação internacional (SCOTT,1997; BENKO, 2001).

Nessa mesma perspectiva, alguns pesquisadores procuram chamar a atenção no Brasil para uma questão significativa mais ampla, constitutiva de uma "mudança paulatina de escala", ou de uma nova recomposição dos espaços frente às novas tendências da evolução econômica internacional e globalizada. Trata-se de uma mutação geopolítica maior das condições de produção, de competência e de interdependência. Se na escala superior consolida-se a criação ou o reforço dos blocos econômicos (no começo principalmente como mercados comuns, e logo evoluindo para espaços político e economicamente unidos), na escala mais baixa, com a descentralização do Estado, nota-se a busca por um reforço das unidades territoriais no nível regional e local (MÜLLER, 2000; CASTRO, 2010; PIRES, 2015).

O reforço do território construído no local é um elo nas cadeias e nos circuitos que o liga aos outros lugares, assim como todos os demais, direta ou indiretamente, são elos nas cadeias que o prende. Essas cadeias e circuitos espaciais são mais visíveis e tangíveis na dinâmica econômica do desenvolvimento subnacional local, mas na dinâmica social e política são mais elásticas, mais variáveis, mais mutáveis.

Neste novo contexto histórico e institucional, o desafio para as ciências sociais de cunho institucionalista, e em especial para a economia e a geografia política, está em não deixar que se privilegie a análise do desenvolvimento em apenas uma das escalas da nova ordem mundial acima citada, em detrimento das demais existentes. Todas elas definem recortes de persistência da medida geográfica das ações institucionais, de modo que produzem escalas de governança e regulação de conflitos dos fenômenos políticos, econômicos e 
sociais. Na realidade, esses fenômenos não se confinam a uma ou outra escala isoladamente, mas, ao contrário, se articulam constantemente entre si através de redes de organizações e instituições, através de avanços cada vez mais significativos na tecnologia dos meios de comunicação e transporte.

Esse conjunto de mutações territoriais do espaço econômico e geográfico, em meio à reorganização das unidades de produção na globalização, tornou evidente a importância das relações humanas fora do mercado, como uma nova organização dos sistemas produtivos nacionais e locais. No desenvolvimento socioeconômico do território, trata-se de um novo modo de relações entre atores, como um modo singular de sinergias culturais que ultrapassam a relação mercantil (PECQUEUR, 2000). Em vez de um recuo à economia mundial, os processos de desenvolvimento territorial permitem uma adaptação das nações para traçar as vias das suas zonas "difíceis" e "intermediárias" à mundialização dominante. Ele pode permitir que essas zonas encontrem o seu próprio caminho, valorizem seus recursos específicos e promovam uma governança particular, contornando as lógicas globalizadas e desterritorializadas (CAMPAGNE, PECQUEUR, 2014).

Portanto, o renascimento dos meios locais e regionais na qualidade de núcleos da organização econômica, cultural e política oferecem novas e inesperadas possibilidades para a renovação da vida comunitária e do desenvolvimento local. A democracia e a cidadania tomam um novo sentido no contexto da sociedade local, com a criação de novas identidades e vocações locais e de novas ações democráticas. Assim, a realização de uma nova visão de política local constrói-se em relação com o novo contexto global: ou seja, um desenvolvimento territorial sustentável fundado sobre a solidariedade, uma ferramenta indispensável para construir uma comunidade mais forte, mais competente, mais equilibrada e, portanto, melhor compreendida pelos povos que a compõem. Nesse contexto, a estratégia de fragmentar a produção por um amplo espaço globalizado impõe novos patamares de negociações entre Estados e empresas, cuja decisão de localização final depende do desiderato das elites que os representam e do projeto de nação que elas têm em mente. É nesse contexto que a escala do lugar adquire um papel importante e a representação local pode ampliar bastante o espaço da sua política. Assim, os territórios locais 
aparecem como a arena privilegiada dos conflitos e opção de coordenação local em reação às pressões da globalização (CASTRO, 2010, p. 240-1). Nessas condições, o espaço-território construído socialmente pode transformar-se no ator coletivo do desenvolvimento, bem como no foco da estratégia dos movimentos sociais na construção de uma sociedade justa e sustentável.

Esta coordenação espacial dos conflitos constitui uma forma de governança política localizada, recheada de aspectos econômicos e sociais específicos do lugar. Assim, a governança territorial se refere a um processo de coordenação entre atores de diferentes naturezas (produtivas, associativas, privadas, autoridades públicas ou autoridades locais), com recursos assimétricos, reunidos em torno de questões territorializadas e contribuindo com o uso de ferramentas e estruturas apropriadas ao desenvolvimento, às vezes concertadas, às vezes conflituosas, de projetos conjuntos para o desenvolvimento territorial. Portanto, a governança dos territórios é uma interação entre forças que pressionam pela cooperação e outras pelo conflito (TORRE, 2010). No Brasil, são registradas inúmeras modalidades de governança territorial, em vários estados do país, nas quais se destacam os Conselhos Regionais e Territoriais, os Comitês de Bacias Hidrográficas, os Conselhos Turísticos, as Câmaras Setoriais da Agroindústria e os Comitês Gestores de Arranjos Produtivos Locais (PIRES et al, 2011).

Desta forma, o conceito e as práticas de governança territorial sugere que se coloque o acento nas formas de coordenação horizontal e vertical da ação pública, acompanhado de uma descentralização do poder do Estado em proveito de outras autoridades estatais (a justiça, as autoridades independentes), das coletividades territoriais e de componentes da sociedade civil (BOURDIN, 2001, p. 137). Assim, as estruturas de governança, quando abordadas em âmbito intranacional local, não podem ser reduzidas somente aos limites dos municípios e de suas estruturas político-administrativas. A convergência de cadeias produtivas e de redes de agentes locais mobilizados endogenamente (desde a base da tessitura social e não somente no planejamento outorgado) se faz, mormente, em contextos socioespaciais inéditos.

Diante deste componente da geografia do desenvolvimento desigual, é necessária uma visão multiescalar da federação brasileira e das modalidades de 
governança possíveis, a partir da ótica dos atores envolvidos. Esses contextos espaciais podem variar desde uma simples aglomeração (concentração de atividades econômicas heterogêneas coordenadas pelos preços do mercado), passando para uma especialização (concentração de empresas em torno de uma mesma atividade ou produto e que resulta em complementaridades, externalidades e projetos comuns) ou atingindo uma especificação produtiva, portadora de recursos específicos (existência de estruturas e formas de coordenação públicas e/ou privadas que internalizam os efeitos externos e dirigem o tecido econômico local).

O Esquema 1 procura sintetizar as hierarquias espaciais vigentes e emergentes no Brasil globalizado, e a diversidade de escalas de governança no interior do território brasileiro (PIRES, 2018). Inicialmente com o Presidente Fernando Henrique Cardoso, e, posteriormente com o Presidente Lula e a Presidente(a) Dilma Rousseff, a política de inserção do Brasil na escala internacional foi predominante. São exemplos disso a maior inserção na OMC e a integração com o MERCOSUL e o BRICS. Também evoluiu a noção de uma política de desenvolvimento sustentável local e regional, do Programa do Desenvolvimento Local, Integrado e Sustentável - DLIS (FRANCO, 1999) para a nova Política Nacional de Desenvolvimento Regional - PNDR (ARAÚJO, 200o), voltada para uma sociedade brasileira que supõe ativa, participativa e propositiva. 


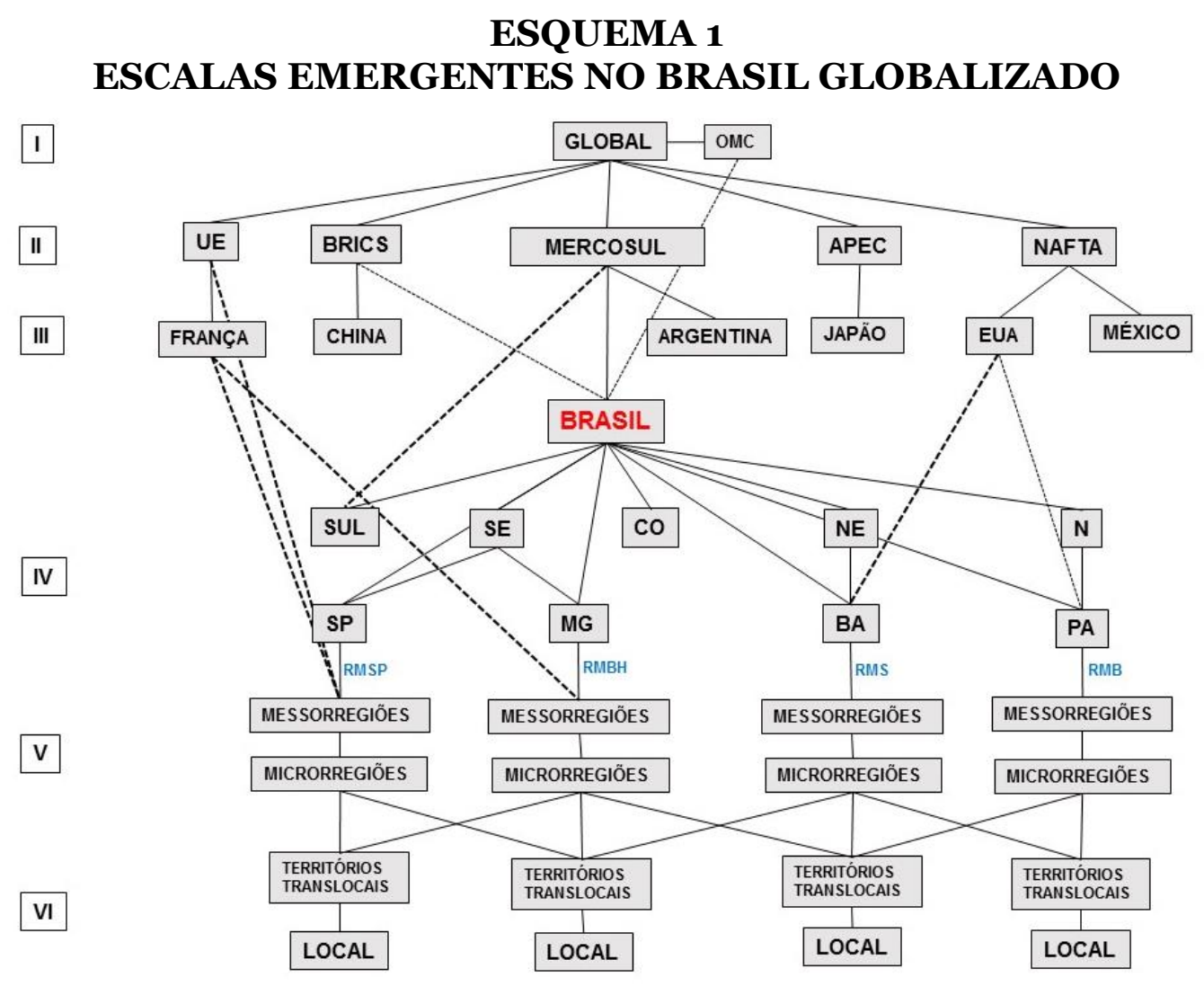

Elaboração própria.

O recorte das grandes regiões continua atrelado às noções de regiõesproblemas e a velha política regional clientelista das Superintendências Regionais com os governadores dos estados da federação. Neste âmbito, além da importância que ganharam as mesorregiões e microrregiões para a política pública do Estado, a grande recomposição territorial ocorreu entre o município e a meso e micro regiões. O grande desafio, teórico e prático, continua sendo identificar o recorte geográfico da nova escala das ações públicas, agora espremida entre o local e a mesorregião e as suas ligações com as escalas das grandes regiões do Brasil, dos blocos regionais e do mundo (PIRES, 2018).

São nesses intervalos espaciais que são realizados os consórcios e as modalidades de governanças, seja setorial ou territorial. Caberia a PNDR propor critérios para a criação e institucionalização desses compromissos em pactos regionais para a descentralização do desenvolvimento. 


\section{A CONSTRUÇÃo NECESSÁria dAS ESCALAS NAS POLÍTICAS DE DESENVOLVIMENTO NACIONAL}

Diante do melancólico período FHC de quase suspensão das políticas regionais, a retomada da questão regional nos governos Lula acaba por gerar grandes expectativas de mudanças entre técnicos, estudiosos e militantes do tema. Desta forma, ressurge no cenário político hegemônico conciliar a histórica ampliação do mercado de consumo de massa com o combate às desigualdades sociais e regionais, um dos mais renitentes resquícios do modelo brasileiro de desenvolvimento concentrador (KARAM, 2013, p. 113).

O Esquema 2 apresenta uma estruturação das escalas de poder, de ações políticas e econômicos possíveis das relações entre Estado-economiasociedade no território brasileiro, e as suas relações com o mundo exterior através dos blocos de Estados-Nação e das organizações globais. Ele procura mostrar as implicações da intensificação fragmentada do crescimento econômico endógeno em um número significativo de regiões brasileiras, reconhecidas como os novos motores do desenvolvimento nacional, que deram origens a mobilizações de inúmeros territórios, envolvidos na criação da PNDR no período 2003-2014 (PIRES, 2018).

No mapa da sociedade brasileira, esse quadro de variedade de escalas geográficas contém profundas desigualdades regionais, apresentando enormes desafios na construção de uma política nacional de governança multiescalar (multinível) do desenvolvimento territorial, pois envolve modificar vários aspectos políticos e econômicos estruturantes da questão regional e federativa. Entre os principais deles, pode-se destacar a concepção e implantação de diferentes mecanismos democráticos de participação social, mas também a montagem e aplicação de arranjos institucionais de cooperação vertical e horizontal (BRASIL, 2012, p. 16). 
ESQUEMA 2

AS ESCALAS DE AÇÕES POLÍTICAS E ECONÔMICAS NA PRODUÇÃO E ORGANIZAÇÃO DOS TERRITÓRIOS BRASILEIROS

GLOBAL (OMC)

\section{AMÉRICA LATINA}

\begin{tabular}{|c|}
\hline BLOCOS DE ESTADOS-NAÇÃO \\
Mercosul, Brics \\
\hline
\end{tabular}

\begin{tabular}{|c|}
\hline \multicolumn{3}{|c|}{ ESTADO NACIONAL (PNDR) } \\
\multicolumn{1}{|c|}{ Política Nacional de Desenvolvimento Regional } \\
\hline
\end{tabular}

\begin{tabular}{|c|}
\hline \multicolumn{2}{|c|}{ ESTADOS DA FEDERAÇ̃̃̃ (PNDR) } \\
São Paulo, Minas Gerais, Bahia \\
\hline $\begin{array}{c}\text { REGIÕES METROPOLITANAS (PNDR) } \\
\text { Região Metropolitana de Campinas }\end{array}$ \\
\hline
\end{tabular}

\begin{tabular}{|c|}
\hline \multicolumn{2}{|c|}{$\begin{array}{c}\text { MESOREGIÕES (PNDR) } \\
\text { Mesorregião de Piracicaba }\end{array}$} \\
\hline \multicolumn{1}{|c|}{$\begin{array}{c}\text { MICROREGIÕES (PNDR) } \\
\text { Micro Região de Rio Claro }\end{array}$} \\
\hline $\begin{array}{c}\text { REGIÕES PROGRAMAS (PNDR) } \\
\text { Xingu, Entorno da BR 163 e Ilha do } \\
\text { Marajó }\end{array}$ \\
\hline
\end{tabular}

\begin{tabular}{|c|}
\hline TERRITÓRIOS (PNDR) \\
Bacias Hidrográficas \\
Câmaras Setoriais da Agroindústria \\
APLs da Indústria \\
Circuitos de Turismo \\
Cultura e Tradição \\
\hline
\end{tabular}

\begin{tabular}{|c|}
\hline $\begin{array}{c}\text { AGLOMERADOS URBANOS } \\
\text { Jundiaí e Piracicaba }\end{array}$ \\
\hline CIDADES POLO (PNDR) \\
\hline $\begin{array}{c}\text { LOCAL (PNDR) } \\
\text { Município de Rio Claro }\end{array}$ \\
\hline
\end{tabular}

FONTE: Elaboração própria (PIRES, 2018)

Esses movimentos de recomposição de escalas foram promovidos pelo Estado brasileiro em diferentes regiões, na busca de convergências com dois sentidos aparentemente opostos: de um lado, através de políticas estabelecidas 
com o objetivo de ampliar as relações internacionais das regiões e, de outro, fortalecer o desenvolvimento endógeno de Arranjos Produtivos Locais, através da pressão da descentralização do poder do Estado pela sociedade civil.

Como pode ser visto, a construção de territórios de coordenação dos interesses locais e regionais se manifestam através de Câmaras setoriais, Consórcios intermunicipais, Conselhos ou Comitês gestores, Agências ou Fóruns de desenvolvimento, todos voltados para a governança das políticas públicas regionais e territoriais. São situações mistas e raras, de autonomia relativa e sem domínio unilateral ex-ante. Cada uma dessas formas e modalidades de coordenação da governança no Brasil pode conduzir a diferentes processos de desenvolvimento territorial. Nesse contexto, o território é a base material e simbólica dos processos de desenvolvimento, enquanto a governança territorial é o mecanismo imaterial de coordenação coletiva exemplar das ações dos atores. Nenhum dos dois existe sem o outro.

Nesse sentido, a identificação da escala intranacional constitui o locus da nova base política e material da governança territorial, uma espécie de campo de forças sociais coletivas em constante mudança na região e o município, um lugar do exercício de dialéticas entre as escalas geográficas e o poder político do Estado. Ela acolhe conflitos e coerências com os compromissos estabelecidos, e se organiza segundo um conjunto de regras e de instituições que são parcialmente elaboradas no nível local ou regional, no ambiente institucional do Estado nacional (PIRES, MÜLLER, VERDI, 2006, p. 442). Nessa escala subregional, a sociedade civil local é chamada para tratar de problemas imediatos, reorganizando seus espaços do cotidiano, reconfigurando politicamente os lugares, criando novas escalas de ação e alterando a própria agenda política do Estado (CASTRO, 2010, p. 224). Na escala mundial, a redução das disparidades entre indivíduos, territórios e regiões foi identificada como um componentechave para o avanço do modelo misto de crescimento e desenvolvimento brasileiro, orientado para a exportação e impulsionado pela demanda interna (OCDE, 2013, p. 90).

Este debate da espacialidade do desenvolvimento brasileiro retoma o caso da unidade nacional mal resolvida da questão regional da nossa federação, das persistências de elementos arcaicos numa sociedade que se moderniza à 
custa dos contrastes sócio econômicos e inter-regionais abissais (OLIVEIRA, 1993). Assim diante da complexidade que cerca este debate sobre o desenvolvimento das regiões brasileiras na era da globalização, parece surgirem novas reflexões sobre as condições de uma questão territorial em construção no país, a partir da avaliação de que os termos originais da questão regional, embora ainda vigentes, estão superados (ARAÚJO, 2007). Nesse quadro, é plausível supor que, cada vez mais, torna-se necessária no país uma estratégia de coordenação do desenvolvimento formulada sob múltiplas escalas geográficas, e não apenas a macrorregional, mesorregional ou microrregional. Desta forma, a nova fragmentação territorial assume a forma de questão geopolítica de múltiplas escalas, tornando a gestão do desenvolvimento indissociável da gestão do território, uma vez que é neste que os laços simbólicos e materiais formam a identidade e forjam unidade (KARAM, 2013, p. 99; CASTRO, 2010; PIRES, 2015).

Com o golpe parlamentar de 2016, o Vice-Presidente Michel Temer altera a condução da política econômica, retomando a agenda liberal ortodoxa, reduzindo o teto de gastos públicos, flexibilizando ainda mais a legislação trabalhista e retomando a reforma da previdência. Em 2018, com a eleição de Jair Bolsonaro (Partido Social Liberal - PSL), contra o adversário Fernando Haddad (PT), sob orientação do seu guru e ideólogo Olavo de Carvalho, na Virgínia (EUA), e do economista ultraliberal Paulo Guedes, o novo governo procura destruir seus rivais, iniciando uma guerra cultural e econômica alucinada contra a esquerda e os democratas republicanos. Nos primeiros cem dias do governo, se destacam: i) um novo nacionalismo, sem nenhum projeto desenvolvimentista, voltado para um mundo de países mais isolados, mais fechados politicamente, menos apto a cooperar e, por isso, mais dispostos à guerra; ii) integrar o país à economia global e promover o livre comércio, mas com subserviência à política externa norte-americana em detrimentos aos blocos supranacionais; e iii) reduzir os gastos públicos retomando a reforma da previdência, as privatizações da infraestrutura física, dos bancos públicos e das empresas estatais. Nesse novo ambiente de ações de direita e políticas liberais ortodoxas, opostas aos governos anteriores, além da perspectiva de retrocesso democrático evidente, o desenvolvimento brasileiro encontra-se ameaçado. 


\section{CONCLUSÕES}

A reflexão crítica sobre a continuidade do regime liberal intervencionista durante os períodos Lula e Dilma é uma questão teórica e política a ser enfrentada pelos estudiosos, de todas as correntes políticas, mas em especial, pelas críticas e autocríticas das forças de esquerda e intelectuais desenvolvimentistas e socialdemocratas.

É claro que vários mecanismos de intervenção do Estado foram realizados nesses governos, possíveis em um momento de crescimento econômico e sem as limitações de divisas internacionais. Entretanto, é evidente que várias mudanças estruturais não foram realizadas, como o enfrentamento da questão do rentismo, a realização de uma profunda reforma tributária para reduzir o caráter concentrador da arrecadação de impostos e contribuições, a reforma política para reduzir o número de partidos de aluguel, a descentralização do Estado para distribuição do poder e aumentar a participação social, entre outras reformas fundamentais.

No período de 2003 a 2014, apesar do crescimento econômico e da implementação de novos arranjos institucionais, as reformas e políticas governamentais não foram suficientes para conduzir o país a uma nova via de desenvolvimento. Em 2014, os grandes desafios do desenvolvimento brasileiro ainda eram os mesmos de antes: i) incapacidade de implementação do pacto federativo, para produzir resultados socialmente desejados pela população; ii) descentralização do Estado e controle das políticas públicas governamentais; e iii) inclusão social das populações e regiões mais pobres. Um diagnóstico objetivo e desapaixonado da situação do país mostra que a economia tem disfunções, os monopólios, oligopólios e cartéis dominam a formação de preços. O sistema tributário é ineficiente e concentrador, o orçamento é perdulário e rígido. A cobertura do saneamento e o déficit habitacional são vergonhosos.

A política econômica nos quatro mandatos de Lula e Dilma foi muito oscilante, impedindo a possibilidade de transformações significativas nos rumos do desenvolvimento brasileiro. Contribuíram para este quadro, a grande quantidade de partidos nas bases da coalizão política desses governos.

Apesar da politização das políticas de estímulo ao consumo e de acesso a bens públicos, estes benefícios não foram incorporados pela maioria da 
população como um resultado de uma deliberada opção política do governo, mas resultavam de forças decorrentes do esforço individual, e, muitas vezes, até refletiam pretensas intervenções divinas. Quando a crise se instala, especialmente depois do golpe de 2016, estes beneficiários das políticas de aumento do consumo não tem a menor fidelidade com os governos que viabilizavam a expansão do seu consumo.

No campo da economia política, a interação histórica entre política, economia e sociedade em um país com grandes desigualdades regionais, precisa ser considerada na concepção e na aplicação dos modelos de desenvolvimento e nas disputas políticas partidárias. Ela gera uma estrutura de incentivos (fiscais e regionais) que está na base do predomínio das práticas clientelistas e de patronagem na política brasileira. Ela é parte da explicação das coalizões fisiológicas, em lugar das almejadas coalizões programáticas ou ideológicas.

No campo específico da PNDR, os desafios da mobilização e da articulação dos atores e regiões para a prática do desenvolvimento e da governança territorial se devem, em particular, à complexidade do sistema federativo brasileiro, mas também ao caráter da participação organizada da sociedade civil na política brasileira; a escassez de mecanismos de coordenação e articulação atuantes entre União, Estados e Municípios; à estrutura específica do modelo de repartição de recursos entre as instâncias de poder e à lógica de atuação historicamente setorial dos programas de governo. Em seu conjunto, essas variáveis têm interposto sérios obstáculos a uma abordagem integrada da ação da territorialidade da política pública, tal como requerida por um projeto de fortalecimento da base produtiva e da oferta de serviços públicos em regiões menos desenvolvidas do país.

Nesse novo contexto histórico e institucional, o novo desafio para a PNDR, e, em especial para as economias e sociedades locais e regionais, está em não deixar que se privilegie a estratégia de desenvolvimento em apenas uma das escalas do novo ordenamento do território brasileiro, em detrimento das demais sugeridas. Todas elas definem recortes de persistência da medida das ações do Estado, de modo que produzem escalas de regulação de conflitos dos fenômenos políticos, econômicos e sociais que surgem no âmbito regional. Na realidade, 
esses fenômenos não se confinam a uma ou outra escala isoladamente, mas, ao contrário, se articulam constantemente entre si.

Desta forma, o período 2003-2016 encerra uma etapa da ordem democrática brasileira sobre bases mais estáveis, iniciada em 1988 e interrompida em 2016, com o golpe parlamentar que retirou a Presidente Dilma do poder. A partir de então, com o governo de Michel Temer, o debate do desenvolvimento brasileiro saiu da pauta do congresso. Assim, com o retorno da política econômica neoliberal sem desenvolvimentismo, agravada no Governo Bolsonaro, o Projeto de Lei da PNDR foi parar na gaveta do Senador Fernando Bezerra, hoje no Governo Bolsonaro.

\section{REFERÊNCIAS BIBLIOGRÁFICAS}

ABRANCHES, S. Presidencialismo de coalizão: raízes e evolução do modelo político brasileiro. São Paulo: Companhia das Letras, 2018.

ARAÚJO, T. B. de. Por uma política Nacional de Desenvolvimento Regional. In: Ensaios sobre o Desenvolvimento Brasileiro: heranças e urgências. Rio de Janeiro: Revan, 2000. p. 71-82.

ARAÚJO, T. Brasil: desafios de uma Política Nacional de Desenvolvimento Regional contemporânea. In.: Diniz, C. (org.). Políticas de Desenvolvimento Regional: desafios e perspectivas à luz das experiências da União Européia e do Brasil. Brasília: Ed. UnB, 2007

BASTOS, P.P.Z. A economia política do novo-desenvolvimentismo e do social desenvolvimentismo. Economia e Sociedade, Campinas, v. 21, Número Especial, p. 779-810, dez. 2012.

BASTOS, P.P.Z. Que horas ela volta? - Economia política e política econômica de Lula e Dilma. In.: MARINGONI, MEDEIROS (Orgs.). Cinco Mil Dias: o Brasil na era do lulismo. São Paulo: Boitempo / Fundação Lauro Campos, 2017, p.77-89.

BENKO, G. A recomposição dos espaços. In Interações - Revista Internacional de Desenvolvimento Local, volume 1, número 2, março, pp.7-12, 2001.

BENKO, G. Economia, Espaço e Globalização na aurora do século XXI. São Paulo: Hucite, 1996.

BIELSCHOWSKY, R. Estratégia de desenvolvimento e as três frentes de expansão no Brasil: um desenho conceitual. In.: Economia e Sociedade. Campinas, v. 21, Número Especial, p. 729-747, dez. 2012 
BOURDIN, A. A Questão Local. Rio de Janeiro: DP\&A, 2001

BOYER, R. L'après-consensus de Washington: institutionnaliste et systémique?. In.: L'Année de la régulation, v. 5, p.13-56, 2001-2002. Ed. Association recherche et regulation - Paris: Presses de Sciences Po. 2001.

BRASIL - Ministério da Integração Nacional (2012). I conferência Nacional de Desenvolvimento Regional. Texto de Referência (Resumo Executivo). Brasília, julho.

BRESSER-PEREIRA., L. C. Teoria novo-desenvolvimentista: uma síntese. Comunicação. Centro Internacional Celso Furtado: Rio de Janeiro. 2016, p.

BRUNO, M.; CAFFÉ, R. Estado e financeirização no Brasil: interdependências macroeconômicas e limites estruturais ao desenvolvimento. Economia e Sociedade, Campinas, v. 26, Número Especial, p. 1031-1068, dez, 2017.

CAMPAGNE, P., PECQUEUR, B. Le Développement Territorial: une réponse emergente à la mondialisation. Paris, Éditions Charles Léopold Mayer, 2014.

CASTRO, I. E. Geografia e Política. Território, escalas de ação e instituições. Rio de Janeiro: Bertrand Brasil, 2010

FRANCO A. de. Por que precisamos de Desenvolvimento Local Integrado e Sustentável? Rio de Janeiro, 1999

FURTADO, C. Desenvolvimento e Subdesenvolvimento. 1961

GABRIELLI DE AZEVEDO, J.S. Olhar o Passado para Orientar o Futuro: diálogo com duas propostas. Mimeo, 2017

GOTTDIENER, M. A Produção Social do Espaço Urbano. São Paulo: Edusp, 1993

GUELLEC, Dominique e RALLE, Pierre. Les nouvelles théories de la croissance. Ed. La Decouverte, Paris, 2001.

HARVEY, D. A Produção Capitalista do Espaço. São Paulo: Annablume, 2001.

JESSOP, B. O Estado, o Poder, o Socialismo de Poulantzas como um Clássico Moderno. Revista Sociologia e Política, v. 17, n. 33, p. 131-144, jun 2009.

KARAM, Ricardo (2013). A Questão Regional na Era Lula: uma análise de ideias, atores e interesses. Rio de Janeiro, Beco do Azougue

LAVINAS, L. How social developmentalism reframed social policy in Brazil. New Political Economy, mar. 2017

MARINGONI, G., MEDEIROS, J. (Orgs.). Cinco Mil Dias: o Brasil na era do lulismo. São Paulo: Boitempo / Fundação Lauro Campos, 2017. 
MILIBAND, R. O estado na sociedade capitalista. Rio de Janeiro: Zahar, 1972.

MOLLO, M. D. L. R. A concepção marxista de Estado: considerações sobre antigos debates com novas perspectivas. Revista Economia (ANPEC), v. 2, n. 2, 2001, p. 347-389.

MOLLO, M. D. L. R.; AMADO, A. M. O debate desenvolvimentista no Brasil: tomando partido. Economia e Sociedade, v. 24, n. 1(53), p. 1-28, Abril 2015.

MÜLLER, G. Região: descentralização na globalização. In Revista REDES, vol. 5, n.2, EDUNISC, Santa Cruz do Sul, p. 9-25, 2000.

OCDE. L'Économie Mondiale: 1820-1992. Analyse et Statistiques. Paris, 1995

OCDE. Relatório Territorial da OCDE: Brasil. Brasília: 2013.

OLIVEIRA, F. de. A Questão Regional: a hegemonia inacabada. Estudos Avançados, São Paulo, vol 7, n. 18, mai/ago., 1993

OLIVEIRA, F. Hegemonia às avessas. In: OLIVEIRA, F. de; BRAGA, R.; RIZEK, C. (orgs.). Hegemonia às Avessas: economia, política e cultura na era da servidão financeira. São Paulo: Boitempo, 2010.

PAULANI, L.M. Desenvolvimento, planejamento e investimento público. . In.: MARINGONI, MEDEIROS (Orgs.). Cinco Mil Dias: o Brasil na era do lulismo. São Paulo: Boitempo / Fundação Lauro Campos, 2017, p.91-99.

PECQUEUR, B. Le Développement Local, Ed. Syros, 2ème édition, Paris, 2000.

PIRES, E.L.S. A recomposição das escalas de governança, Estado e desenvolvimento territorial no Brasil. GeoTextos, vol. II, n. 1, julho, 2015, p. 113137.

PIRES, E.L.S. As escalas da governança territorial no Brasil: modalidades e regulação. In.: Anais do III CONGEO, 2018.

PIRES, E.L.S.; FUINI, L. L.; MANCINI, R. F.; PICCOLI NETO, D. P. Governança Territorial: Conceitos, Fatos e Modalidades. Rio Claro: UESP IGCE: Programa de Pós-Graduação em Geografia, 2011.

PIRES, E.L.S.; MÜLLER, G.; VERDI, A.R. Instituições, Territórios e Desenvolvimento Local: Delineamento preliminar dos aspectos teóricos e morfológicos. Geografia - Associação de Geografia Teorética - Rio Claro, SP: v. 31, set./dez, 2006, p. 437-454.

POULANTZAS, N. O Estado, o Poder, o Socialismo. Rio de Janeiro: Graal, 1980.

PREBISCH, R. O falso dilema entre desenvolvimento econômico e estabilidade monetária. Revista de Ciências Econômicas, 1961. 
SADER, E. (org.). 10 anos de governo pós-neoliberal: Lula e Dilma. São Paulo, SP: Boitempo; Rio de Janeiro: FLACSO Brasil, 2013.

SANTOS, M. A Natureza do Espaço. Técnica e Tempo. Razão e Emoção. São Paulo: Hucitec, 1996.

SCOTT, A. J., Regions and the World Economy, Oxford University Press, 1997.

SEN, A. K. Desenvolvimento como liberdade. São Paulo: Companhia das Letras, 2000.

SICSÚ, J. Governos Lula: a era do consumo? Texto de Discussão o21-2017. Instituto de Economia. UFRJ: Rio de Janeiro, 2017.

SICSÚ, J. Por que novo-desenvolvimentismo? Revista de Economia Política, v. 27, n. 4 (108), out./dez, 2007.

SINGER, A.; LOUREIRO, I. (orgs.). As Contradições do Lulismo: a que ponto chegamos? São Paulo: Boitempo, 2016.

SMITH, N. Desenvolvimento Desigual. Rio de Janeiro: Ed. Bertand Brasil S.A., 1988.

TORRE, A. Conflitos e governança dos territorios. Raizes, V. 28 ns. 1 e 2 ev. 29, 1, 2010, p.109-120.

Recebido em maio de 2019 Aceito em junho de 2019 